\title{
Pengaruh Kualitas Produk, Harga, dan Promosi Terhadap Keputusan Pembelian Powder Drink Pada Jakarta Powder Supply (JPS) Cabang Banyuwangi
}

\author{
Tutut Hariyadi \\ Universitas 17 Agustus 1945 Banyuwangi, Banyuwangi, Indonesia \\ Email: tututhariyadi1958@gmail.com \\ Email Penulis Korespondensi: tututhariyadi1958@gmail.com \\ Submitted: 23/09/2021; Accepted: 29/11/2021; Published: 30/11/2021
}

\begin{abstract}
Abstrak-Persaingan di era globalisasi seperti sekarang ini menuntut pemasar untuk selalu mengembangkan dan merebut pangsa pasar. Kegiatan pemasaran akan mencapai hasil yang baik, maka produsen harus mengetahui terlebih dahulu apa yang menjadi kebutuhan dan keinginan konsumen, sehingga produk yang ditawarkan akan sesuai dengan kondisi pasar. Penelitian kuantitatif ini bertujuan untuk menganalisis dan menguji pengaruh kualitas produk, harga dan promosi terhadap keputusan pembelian dengan teknik simple random sampling dengan jumlah responden sebanyak 85 orang (pembeli) powder drink di JPS (Jakarta Powder Supply) Cabang Banyuwangi. Adapun teknik pengumpulan datanya menggunakan kuesioner.
\end{abstract}

Kata Kunci: Citraimerek, Harga, Kualitasiproduk, Promosi, Keputusan.Pembelian, Minati Beli, SEM PLS.

Abstract-Competition in the current era of globalization requires marketers to always develop and seize market share. Marketing activities will achieve good results, so producers must know in advance what the needs and desires of consumers are, so that the products offered will be in accordance with market conditions. This quantitative study aims to analyze and test the effect of product quality, price and promotion on purchasing decisions using simple random sampling technique with 85 respondents (buyers) of powder drink at JPS (Jakarta Powder Supply) Banyuwangi Branch. The data collection technique used a questionnaire.

Keywords: Brand Image, Price, Product Quality, Promotions, Purchasing Decisions, Buying Interests, SEM PLS.

\section{PENDAHULUAN}

Persaingan di era globalisasi seperti sekarang ini menuntut pemasar untuk selalu mengembangkan dan merebut pangsa pasar. Dalam melaksanakan pemasaran yang berhasil, produsen harus mengetahui terlebih dahulu apa yang menjadi kebutuhan dan keinginan konsumen, sehingga produk yang ditawarkan akan sesuai dengan permintaan konsumen. Dalam dunia usaha keputusan pembelian menjadi isu yang sangat menarik, alasan yang pertama karena persaingan yang semakin ketat, selain itu kebutuhan dan keinginan konsumen selalu mengalami perubahan bahkan cenderung meningkat dari waktu ke waktu maka perusahaan perlu mengadakan suatu riset pemasaran dalam usaha untuk mengetahui produk apa yang sebenarnya dibutuhkan dan diinginkan oleh konsumen.

Keterkaitan kualitas produk terhadap keputusan pembelian yang diimplementasikan kesesuaian kualitas produk dengan harapan konsumen. Menurut Schiftman dan Kanuk dalam Lindawati (2005 : 52) menyatakan bahwa "Konsumen percaya bahwa berdasarkan evaluasi mereka terhadap kualitas produk akan dapat mempertimbangkan produk mana yang akan mereka beli". Keterkaitan harga terhadap keputusan pembelian menurut Kotler dan Amstrong dalam Prasetyo (2008 : 108) "Semakin tinggi harga maka keputusan pembelian semakin rendah, sebaliknya jika harga rendah maka keputusan pembelian berubah semakin tinggi”. Oleh karena itu para pengusaha harus jeli dalam menetapkan harga produknya ke pasar agar produk tersebut sukses di pasar.

Faktor lain yang mempengaruhi keputusan pembelian adalah promosi. Promosi merupakan faktor penting untuk mewujudkan tujuan penjualan perusahaan. Dengan promosi perusahaan dapat mengkomunikasikan produk kepada konsumen. Keunggulan sebuah produk dapat diketahui oleh konsumen dan bisa membuat konsumen tertarik untuk mencoba, kemudian akan mengambil keputusan untuk membeli produk tersebut.

\section{METODE PENELITIAN}

\subsection{Faktor-faktor Dalam Keputusan Pembelian}

Faktor-faktor yang mendorong keputusan pembelian adalah :

a. Kualitas Produk

Menurut Schiftman dan Kanuk dalam Lindawati $(2005,52)$ "Konsumen percaya bahwa berdasarkan evaluasi mereka terhadap kualitas produk akan dapat mempertimbangkan produk mana yang akan mereka beli”.

b. Harga

Menurut Angipora (2002, 268) menyatakan bahwa "Suatu harga berpengaruh terhadap pembelian". Harga memiliki dimensi (indikator) menurut Herman, et. al (2007, 54) meliputi : "keterjangkauan harga, diskon / potongan harga dan cara pembayaran".

c. Promosi 
Menurut Rangkuti (2010, 50) "Promosi adalah kegiatan penjualan dan pemasaran dalam rangka menginformasikan dan mendorong permintaan terhadap produk, jasa dan ide dari perusahaan dengan cara mempengaruhi konsumen agar mau membeli produk dan jasa yang dihasilkan oleh perusahaan".

Menurut Lupiyoadi dan Hamdani $(2006,121)$ "Bauran promosi terdiri dari enam indikator yang meliputi : advertising, salespromotion, personal selling, public relations, direct marketing dan word of mouth".

Sedangkan keputusan pembelian menurut Kotler dalam Nurmawan $(2007,142)$ memiliki empat indikator yang meliputi "kemantapan pada sebuah produk, kebiasaan dalam membeli produk, memberikan rekomendasi kepada orang lain dan melakukan pembelian ulang".

\subsection{Kerangka Konseptual Penelitian}

Hubungan kausal antara variabel kualitas produk, harga, promosi dan keputusan pembelian secara skematis disajikan dalam modal kerangka konseptual penelitian sebagai berikut :

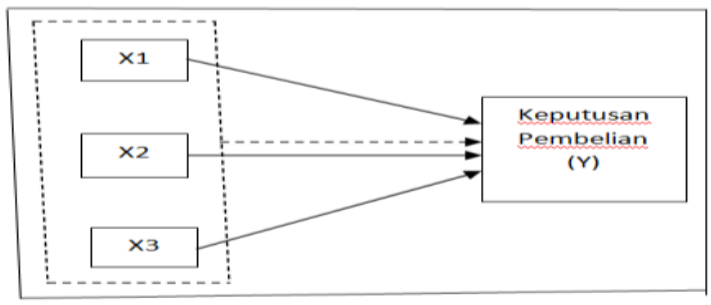

Gambar 1. Kerangka Konseptual Penelitian

\subsection{Hipotesis}

Berdasarkan kerangka konseptual penelitian maka ditetapkan hipotesis sebagai berikut :

a. Diduga kualitas produk, harga dan promosi berpengaruh secara simultan terhadap keputusan pembelian powder drink pada Jakarta Powder Supply (JPS) Cabang Banyuwangi.

b. Diduga kualitas produk berpengaruh secara parsial terhadap keputusan pembelian powder drink pada Jakarta Powder Supply (JPS) Cabang Banyuwangi.

c. Diduga harga berpengaruh secara parsial terhadap keputusan pembelian powder drink pada Jakarta Powder Supply (JPS) Cabang Banyuwangi.

d. Diduga promosi berpengaruh secara parsial terhadap keputusan pembelian powder drink pada Jakarta Powder Supply (JPS) Cabang Banyuwangi.

e. Diduga harga berpengaruh dominan terhadap keputusan pembelian powder drink pada Jakarta Powder Supply (JPS) Cabang Banyuwangi.

\subsection{Populasi dan Sampel}

Penelitian ini merupakan jenis penelitian kuantitatif yang populasinya adalah konsumen produk powder drink pada Jakarta Powder Supply (JPS) Cabang Banyuwangi sebanyak 555 orang. Sementara sampel diambil menggunakan teknik sampel random sampling, menurut Noor $(2011,151)$ "Teknik sampel random sampling merupakan teknik yang paling sederhana. Sampel diambil secara acak, tanpa memperhatikan tingkatan yang ada dalam populasi, tiap elemen populasi memiliki peluang yang sama untuk terpilih sebagai subyek".

Menurut Noor $(2011$ : 158) Adapun rumus yang digunakan dalam penelitian ini adalah menggunakan rumus Slovin yaitu :

$$
\begin{aligned}
& \mathrm{n}=\frac{\mathrm{N}}{1+\left(N^{*} e^{2}\right)} \\
& \mathrm{n}=\text { jumlah elemen / anggota sampel } \\
& \mathrm{N}=\text { jumlah elemen / anggota populasi } \\
& \mathrm{e} \quad=\text { error level (tingkat kesalahan) pada penelitian ini menggunakan 10\% } \\
& \quad \text { Sampel yang didapatkan sebanyak } 85 \text { orang. }
\end{aligned}
$$

\subsection{Instrumen Pengumpulan Data}

Instrumen pengumpulan data menggunakan kuesioner dengan menggunakan skala Likert dengan skala penilaian 1 s/d 5. Kepada responden diharapkan menjawab Sangat Tidak Setuju diberi skor 1, Tidak Setuju diberi skor 2, Biasa Saja diberikan skor 3, Setuju diberi skor 4, dan Sangat Setuju diberi skor 5.

\section{HASIL DAN PEMBAHASAN}

Data yang diperoleh dari aktivitas pengumpulan data kemudian dilakukan pengolahan data sehingga memperoleh hasil sebagai berikut : 


\subsection{Uji Regresi Linear Berganda}

Uji regresi linear berganda digunakan untuk mengetahui besarnya pengaruh variabel-variabel kualitas produk, harga dan promosi terhadap variabel-variabel keputusan pembelian. Model regresi berdasarkan hasil analisis adalah:

$$
\mathrm{Y}_{1}=1,061+0,197 \mathrm{X}_{1}+0,313 \mathrm{X}_{2}+0,253 \mathrm{X}_{3}
$$

Dengan berdasar hasil analisis diatas menunjukkan koefisien regresi dari variabel $\mathrm{x}_{2}(0,313)$ lebih besar dari koefisien regresi variabel $\mathrm{x}_{1}(0,197)$ dan koefisien regresi variabel $\mathrm{x}_{3}(0,253)$. Dengan demikian variabel harga memiliki pengaruh yang lebih besar dibandingkan variabel kualitas produk dan promosi.

\subsection{Koefisien Determinasi}

Dari hasil perhitungan diperoleh hasil koefisien determinasi (Adjusted $\mathrm{R}^{2}$ ) sebesar 64,6\%. Hal ini berarti variabel kualitas produk, harga dan promosi mampu menjelaskan variabel keputusan pembelian sebesar 64,6\%, sisanya sebesar $35,4 \%$ tidak dijelaskan oleh model.

\subsection{Uji Hipotesis}

a. Uji F

Berdasarkan Uji $\mathrm{F}$ ditemukan variabel kualitas produk $\left(\mathrm{x}_{1}\right)$, variabel harga $\left(\mathrm{x}_{2}\right)$, dan variabelpromosi $\left(\mathrm{x}_{3}\right)$ berpengaruh signifikan terhadap variabel keputusan pembelian $(\mathrm{y})$.

b. Uji t

1) Berdasarkan uji t disimpulkan bahwa ada pengaruh yang signifikan dari variabel kualitas produk $\left(\mathrm{x}_{1}\right)$ secara parsial terhadap variabel keputusan pembelian (y).

2) Berdasarkan uji t dapat disimpulkan bahwa ada pengaruh yang signifikan dari variabel harga $\left(\mathrm{x}_{2}\right)$ secara parsial terhadap variabel keputusan pembelian (y).

3) Berdasarkan uji t dapat disimpulkan bahwa ada pengaruh yang signifikan dari variabel promosi $\left(\mathrm{x}_{3}\right)$ secara parsial terhadap variabel keputusan pembelian (y).

Berdasarkan hasil analisis diketahui bahwa variabel yang paling dominan mempengaruhi variabel keputusan pembelian $(\mathrm{y})$ adalah variabel harga $\left(\mathrm{x}_{2}\right)$ dengan nilai t sebesar 3,470, kemudian diikuti variabel promosi $\left(\mathrm{x}_{3}\right)$ dengan nilai t sebesar 2,284 dan variabel kualitas produk ( $\left.\mathrm{x}_{1}\right)$ dengan nilai t sebesar 2,239.

\subsection{Uji Asumsi Klasik}

Berdasarkan hasil uji asumsi klasik diketahui bahwa antar variabel independen tidak mengandung gejala multikolinearitas karena nilai Variance Inflation Factor(VIF) masing-masing variabel tidak lebih besar dari 10. Dan model regresi tidak mengandung gejala heteroskedastisitas karena nilai signifikannya (sig) lebih besar dari nilai alpha $(0,05)$.

\section{KESIMPULAN}

Berdasar hasil analisis Uji regresi linear berganda menghasilkan persamaan, disimpulkan bahwa variabel harga berpengaruh lebih besar terhadap keputusan pembelian $(\mathrm{y})$ dibanding dengan variabel kualitas produk $\left(\mathrm{x}_{1}\right)$ dan variabel promosi $\left(\mathrm{x}_{3}\right)$ yang nilai koefisien regresinya 0,197 dan 0,253 . Hasil uji koefisien determinasi $\left(\mathrm{R}^{2}\right)$ diperoleh hasil adjusted $\mathrm{R}^{2}$ sebesar 64,6\% yang artinya variabel kualitas produk $\left(\mathrm{x}_{1}\right)$, harga $\left(\mathrm{x}_{2}\right)$ dan promosi $\left(\mathrm{x}_{3}\right)$ mampu menjelaskan variasi variabel keputusan pembelian (y) sebesar 64,6\% sedangkan sisanya sebesar 35,4\% tidak dijelaskan oleh model. Berdasarkan hasil uji F didapat hasil F hitung lebih besar dari F tabel $(52,067>2,72)$ artinya secara simultan variabel kualitas produk $\left(\mathrm{x}_{1}\right)$, variabel harga $\left(\mathrm{x}_{2}\right)$ dan variabel promosi $\left(\mathrm{x}_{3}\right)$ berpengaruh signifikan terhadap variabel keputusan pembelian $(\mathrm{y})$. Dengan mendasar uji $\mathrm{t}$ untuk kualitas produk $\left(\mathrm{x}_{1}\right)$ yang $\mathrm{t}$ hitungnya $>\mathrm{t}$ tabel $(2,239>1,989)$, untuk harga $\left(\mathrm{x}_{2}\right) \mathrm{t}$ hitung $>\mathrm{t}$ tabel $(3,4707>1,989)$ dan promosi $\left(\mathrm{x}_{3}\right) \mathrm{t}$ hitung $>\mathrm{t}$ tabel $(2,284>$ $1,989)$ yang artinya masing-masing variabel berpengaruh secara parsial terhadap variabel keputusan pembelian (y). Berdasarkan hasil analisis bahwa variabel harga $\left(\mathrm{x}_{2}\right)$ yang memiliki nilai t sebesar 3,470 adalah variabel yang berpengaruh paling dominan terhadap keputusan pembelian (y). Dengan menggunakan uji asumsi klasik diketahui bahwa antar variabel independen tidak mengandung gejala multikolinearitas karena nilai VIF tidak lebih besardari 10. Disamping itu model regresi tidak mengandung gejala heteroskedastisitas karena nilai signifikannya (sig) lebih besar dari nilai alpha $(0,05)$.

\section{REFERENCES}

Angipora, Marius. 2002. Dasar-dasar Pemasaran. Edisi Kedua. PT. Grafindo Persada, Jakarta.

Arikunto, Suharsimi. 2006. Prosedur Penelitian : Suatu Pendekatan Praktek. PT. Rineka Cipta, Jakarta.

Ghozali, Imam. 2006. Aplikasi Analisis Multivariate dengan Program SPSS. Badan Penerbit Universitas Diponegoro, Semarang. Kotler, Philip. 2006. Manajemen Pemasaran, Jilid III. Edisi 11. Alih Bahasa Benyamin.

Kotler, Philip. 2007. Prinsip-prinsip Pemasaran. Erlangga Jakarta.

Kotler, Philip. 2000. Manajemen Pemasaran. Edisi Milennium. Prenhallindo, Jakarta.

Kotler, Philip. 2009. Manajemen Pemasaran. Edisi12. Cetakan Ketiga. PT. Indeks, Jakarta. 
Ekonomi, Keuangan, Investasi dan Syariah (EKUITAS)

Vol 3, No 2, November 2021, Hal 235-238

ISSN 2685-869X (media online)

DOI 10.47065/ekuitas.v3i2.706

Lupiyoadi, Rambat. 2009. Manajemen Pemasaran Jasa Teori dan Praktik. Salemba Empat. Jakarta.

Ruswaji, R., \& Sulaeman, M. M. (2021). DEVELOPMENT AND INNOVATION OF SENDANG BATIK DESIGN AND MOTIVATION DURING THE NEW NORMAL TIME WITH SIWALAN LEAF AND FRUIT MOTIF. JHSS (JOURNAL OF HUMANITIES AND SOCIAL STUDIES), 5(3), 326-329.

Sugiyono. 2008. Metode Penelitian Bisnis. Alfabeta, Bandung.

Sugiyono. 2009. Statistik untuk Penelitian. Alfabeta, Bandung.

Susanti, I., Syairozi, M. I., \& Lukman, H. Y. W. (2021). Analisis Sistem Manajemen Dalam Pengelolaan Bumdes Di Desa Bluluk. Jurnal Sains Sosio Humaniora, 5(2), 701-710.

Syairozi, M. I. (2017). Aplikasi Akad Musyarakah pada Pembiayaan Unit Usaha Syariah PT Bank Rakyat Indonesia (PERSERO), Tbk. PROCEEDINft, 111.

Tjiptono, Fandy. 2000. Service Quality and Satisfaction. Andi, Yogyakarta.

Tjiptono, Fandy. 2000. Perspektif Manajemen dan Pemasaran Kontemporer. Andi, Yogyakarta.

Tjiptono, Fandy. 2001. Strategi Pemasaran. Andi, Yogyakarta.

Tjiptono, Fandy. 2008. Strategi Pemasaran, Andi, Yogyakarta 